\title{
Extrapolating potential crop damage by insect pests based on land use data: examining inter-regional generality in agricultural landscapes
}

\section{Ken Tabuchi ( $\nabla$ tabuchik@affrc.go.jp )}

Tohoku Agricultural Research Center, NARO https://orcid.org/0000-0002-4662-384X

Akihiko Takahashi

Hokuriku Research Station, Central Region Agricultural Research Center, NARO

Ryuji Uesugi

Tohoku Agriculutral Research Center, NARO

\section{Shigeru Okudera}

Asahikawa Campus, Hokkaido University of Education

\section{Hideto Yoshimura}

Tohoku Agricultural Research Center, NARO

\section{Research Article}

Keywords: area-wide pest management, pecky rice, pest-suppressing landscape, Stenotus rubrovittatus, landscape structure

Posted Date: November 1st, 2021

DOI: https://doi.org/10.21203/rs.3.rs-914458/v2

License: (c) (i) This work is licensed under a Creative Commons Attribution 4.0 International License. Read Full License 


\section{Abstract}

Context

Inter-regional relationships between landscape factors and biological responses under natural conditions are important but difficult to predict because of the differences in each landscape context and local environment.

Objectives

To examine the inter-regional variability in relation to landscape factors and the biological response of an insect pest, we extrapolated a damage prediction model ('the original model') for rice using land-use data. We hypothesized that the original model would be applicable to new regions, but the predictive accuracy would be reduced. We predicted that adjusting the parameter coefficients would improve model performance ('the adjusted model').

\section{Methods}

A field experiment was conducted in two regions that had a similar landscape context with the original region, in different years for each region, for four years in total. The proportion of rice damage and surrounding land-use within a 300-m radius was investigated.

Results

When 'the original model' was assigned to combined data from the original and extrapolated regions, the relationship between observed and predicted values was statistically significant, suggesting that there was an inter-regional common relationship. The relationship was not statistically significant if the model was applied only to the new regions. The adjusted model improved by $14 \%$ compared with the original model.

\section{Conclusions}

These results imply that in this pest-crop system, a common inter-regional biological response to arthropods is likely because of landscape factors, although local environmental factors must be considered. Application of such relationships is needed to identify or prevent pest hazards by offering region-wide management options.

\section{Introduction}

Evaluation of the response of organisms to landscape factors is important for solving basic and applied problems such as species conservation, prediction of the population dynamics of organisms, and pest management (Bianchi et al. 2006; Schellhorn et al. 2015; Miguet et al. 2016). The temporal and spatial effects of landscape factors on the biological responses of organisms vary from region to region (e.g. Miller et al. 2004). Previous studies have reported that the relationships between landscape factors and biological responses depend on dispersal ability, local and inter-habitat movement, population density, habitat related contexts (i.e. size, amount, heterogeneity, and fragmentation), and associated response of organisms (Miguet et al. 2016). Inter-regional variations in landscape context, that is, the amount and spatial pattern of different land cover types surrounding a given site (Moraga et al. 2019), are expected to cause changes in these relationships. However, there has been very little examination of the extent of inter-regional variation in landscape factors, such as land use composition and configuration, and biological responses in similar environments.

Addressing this issue will be valuable in terms of applied ecology, because it offers the prospect of being able to extrapolate environmental hazards, such as the likelihood of pest damage, wildlife and vector-borne diseases, and their management actions. Compared with natural and semi-natural landscapes which are highly diverse and contextually unique, agricultural landscapes, which cover $37 \%$ of global land area (FAO, 2019), have relatively simple plant and animal 
communities. Conventionally managed fields are particularly environmentally homogenous because of the management style of local farmers in terms of mowing, cultivation, and agrochemical use. In agricultural landscapes, especially in intensively managed agricultural environments, comparable responses of organisms to landscape factors may be observed even in different regions because of the similarity of anthropogenic management. Discussions about extrapolation have been a major research focus in applied ecology (Miller, Turner, Smithwick, Dent, \& Stanley 2004). However, few studies of species occurrence have discussed commonality across regions (Vanreusel et al. 2007; Murray et al. 2011), and more complex responses such as crop damage have not been tested using empirical data. Knowing whether there are inter-regional generalities in local ecosystem management that can be applied regionally may help us to develop recommendations for stakeholders for nature conservation and biological management policies.

Stenotus rubrovittatus is one of the most important rice pests in eastern Asian countries including Japan and South Korea (Lee et al. 2009; Tabuchi et al. 2015). A predictive model of rice damage from this insect (known as "pecky rice damage" on brown rice grains), using land use within an effective spatial scale was developed, and a hazard map was prepared based on the model (Tabuchi et al., 2017). This species seldom breeds in rice paddies (Hayashi and Nakazawa, 1988) and the number of individuals of $S$. rubrovittatus invading rice paddy fields is limited by the source habitat of the surrounding landscape. This model predicts rice damage in the focal field using land use data within a 300-m radius, mainly based on the area of source habitat (i. e. pastures and graminoid-dominated fallow fields). Similar results on the effective spatial scale of $S$. rubrovittatus abundance were reported in two independent regions, which are $300 \mathrm{~km}$ away from each other, suggesting some inter-regional generality (Yasuda et al., 2011; Takada et al., 2012). The damage prediction model and the hazard map for $S$. rubrovittatus can be applied to improve management options for the pest and to allocate the optimal labor required for spraying pesticides. It is anticipated that the performance of the predictive model will increase as it becomes available in wider areas. Developing a damage prediction model for pests in a single region that can be applicable to neighboring regions may help to predict pest damage in wider areas, and further enhance the development of effective pest management practices.

To examine whether the inter-regional generality of the relationship between landscape factors and crop damage could be established in agricultural landscapes that have similar contexts, a field study was carried out in two extra regions that had a similar landscape context with the original region, each in a different year of four years in total. The data obtained in two regions were compared with that of the original region of 3 years (Tabuchi et al. 2017). We extrapolated a damage prediction model to two different areas that had similar landscape contexts to the region where the damage prediction model was developed. We hypothesized that the relationship between landscape factors and crop damage would be comparable across regions with similar landscape contexts, and that it would be possible to extrapolate the damage prediction model. We also hypothesized that the accuracy of the model's prediction would be reduced in extrapolated regions presumably owing to the influence of local factors, such as pest abundance variations and associated factors relating local land use patterns, necessitating adjustments in parameter coefficients.

\section{Materials And Methods}

\section{Study insect}

Stenotus rubrovittatus is a major rice pest causing pecky rice in eastern Asian countries including Japan (Lee et al., 2009; Tabuchi et al., 2015). The presence of contaminating pecky rice grains in brown rice results in a lower rice grade and affects the market price. Under Japanese rice quality regulations, there are four grades of brown rice (first, second and third grades, and substandard) based on the percentage of pecky rice: first grade $\leq 0.1 \%, 0.1 \%<$ second $\leq 0.3 \%, 0.3 \%<$ third $\leq$ $0.7 \%$, and $0.7 \%$ < substandard (Ministry of Agriculture, Forestry and Fisheries 2001). Stenotus rubrovittatus occurs mainly in habitats dominated by graminoid weeds (Hayashi and Nakazawa, 1988). The abundance of the species in rice paddy fields increases after the flowering stage of the rice plant, and peaks sharply to make the connection between adults/nymph with rice and graminoid weeds easier. Numbers then decline after a week and increase again approximately 
2 weeks after the first peak (Takeda et al. 2012). Indeed, while S. rubrovittatus nymphs prefer graminoid weeds to rice (Nagasawa and Higuchi 2012) and rice is not a good food resource for developing, the adults of this species prefer rice flowers flavor itself (Hori and Namatame 2013).

As mentioned earlier, Tabuchi et al. (2017) developed a predictive model of pecky rice damage using land use within a 300$\mathrm{m}$ radius which is the effective spatial scale of $S$. rubrovittatus, using a single application of insecticide for stinkbugs and one rice variety, "Hitomebore". The functional spatial scale demonstrated from independent studies with different locations was found to be between 300-m (Yasuda et al. 2011) and $400 \mathrm{~m}$ (Takada et al. 2012). We set the effective functional spatial scale as a 300-m radius from the focal rice paddy fields in this study, based on these independent studies. The major factor affecting pecky rice damage in the predictive model was the area of source habitat for $S$. rubrovittatus. The area of soybean fields was examined as an additional component of the predictive model, but this was only marginally significant. Soybean itself is not a host plant of $S$. rubrovittatus, however, soybean fields that are not well managed for weeds often have high density of graminoid weeds. Moreover, the abundance of S. rubrovittatus (i. e. the number of adult males caught by synthetic sex pheromone-baited traps) was not an important model parameter according to model selection using AIC (Tabuchi et al. 2017).

\section{Study site}

The multi-year field study was conducted in two regions which are located in northern Honshu Island, Japan (Fig. 1, Table 1). Two (2018 and 2020) and three years (2016-2018) studies were performed for Otomo, and Semine region, respectively. The data were compared with the region of the previous study in the Maesawa region from 2011 to 2013 (Tabuchi et al. 2017). Maesawa and Otomo regions were located in Iwate Prefecture, and Semine was located in Miyagi Prefecture. The distances from Otomo, and Semine region to Maesawa were $51.8 \mathrm{~km}$ and $44.6 \mathrm{~km}$, respectively. The study regions were agricultural landscapes dominated by rice paddy fields, with some forests, and other land uses such as crop fields other than rice, open water, and urban areas (Online Resource Fig. S1). In Maesawa and Semine, which were located inland, the other land uses were mainly composed of pastures, fallow fields, and urban areas (Table 2). Otomo was located in a coastal area and forests and rice paddy fields are the major components of the agricultural landscape with small soybean fields, fallow fields and residential areas. Maesawa and Semine were typical of the flat plain agricultural landscapes of northern Honshu Island, and Otomo was typical of agricultural landscapes in the coastal area of northern Honshu Island. In Maesawa, almost $90 \%$ of pastures contained Italian ryegrass, Lolium multiflorum Lam. (Poales: Poaceae), which is one of the major host plants for S. rubrovittatus (Nagasawa and Higuchi 2012). In Semine, pastures contained a mixture of Italian ryegrass and orchard grass Dactylis glomerate L. (Poales: Poaceae). Wild gramineous weeds such as Digitaria ciliaris (Retz.) Koeler, Setaria viridis (L.) P.Beauv., Echinochloa crus-galli (L.) P.Beauv., Imperata cylindrica (L.) Raeusch., and Polypogon fugax Nees ex Steud were observed in fallow fields. In Otomo, there were no pasture fields but several wild gramineous weeds such as $D$. ciliaris, $S$. viridis, E. crus-galli, and I. cylindrica were observed in fallow fields. The average area of source habitats, such as pastures which mainly consisted of Italian ryegrass and graminoid-dominated fallow fields was $11.0 \%$, ranging from $1.3 \%$ to $29.4 \%$, among the regions (Table 1, Online Resource Fig. S1). The study sites in this study lay in a temperate zone. The mean temperature of the three regions over the research period from July to September was $20.3^{\circ} \mathrm{C}$, and mean precipitation per month during field research was $149.1 \mathrm{~mm}$ (Table 1 ).

\section{Experimental design}

To examine the inter-regional generality of the relationship between pecky rice damage and land use, land use-types in the focal area were conducted every year during the multi-year field research periods for two regions, each in a different year of four years in total (Tables 1 and 2). Then the data was compared with the previous data in the Maesawa region from 2011- 
2013 (Tabuchi et al. 2017). We categorized seven land use types, forest, rice paddy fields, soybean, other agricultural fields, source habitats of $S$. rubrovittatus (such as pastures and graminoid-dominated fallow fields), open water, and other land uses (Table 2). We set a research point of $10 \mathrm{~m}$ from the corner of the focal rice paddy field to avoid any effects of $S$. rubrovittatus movement caused by the mowing of paddy field borders (Takeda et al. 2012). Within a 300-m radius around the focal field of each site, each land use type was identified using a combination of aerial photos taken by a commercial UAV (DJI Mavic Pro and DJI Mavic 2 Pro, DJI, Shenzhen, China) and visual field assessment (i.e., ground-truthing), for a total of 6,642 fields. The data were mapped and the area of each land use calculated using ArcGIS 10.4 (ESRI 2016), and an arable field polygon dataset was provided by the Federation of Land Improvement Associations of Iwate Prefecture and Miyagi Prefecture, and Ministry of Agriculture, Forestry and Fisheries (https://www.maff.go.jp/j/tokei/porigon/index.html). The arable field polygon dataset only included arable land parcel information with no information available on planted crops.

Most agricultural field margins were dominated by graminoids, suggesting that each field margin could act as a potential source habitat as previously reported (e.g. Yasuda et al. 2011). We calculated the area of field margin surrounding each focal field using an equation based on the agricultural field area $\left(\mathrm{m}^{2}\right)$ (the area of field margin $=0.3978 \times$ field perimeter $(m)-25.173$ ), where 0.3978 is the coefficient and -25.173 is the intercept (Online Resource Fig. S2). Highly positive relationship was shown between the area of field margin and the field perimeter $\left(R^{2}=0.602, n=33, p<0.001\right)$. The calculated area of the field margin was added as one of the source habitats.

The three regions examined were fine-grained agricultural landscapes, and the average size $( \pm S E)$ of a rice paddy field examined was $0.24 \pm 0.02$ ha (Table 2 ). The average area ( \pm SE) of fields investigated land use of Maesawa, Otomo, and Semine was $0.15 \pm 0.002,0.10 \pm 0.003$, and $0.16 \pm 0.004$ ha, respectively, and significantly differ among regions (Online resource Fig. S3; one-way Anova, $\left.F_{2,6639}=37.86, p<0.001\right)$. Therefore, there was an effect of land use configuration to some extent; however, most fields were in the interquartile range from 0 to 0.4 ha and overlapped, to that the effect was not likely to be serious among regions in this study. The average distance ( \pm SE) between traps set in rice paddy fields was 809 $\pm 49 \mathrm{~m}$, ranging from 596 to $1179 \mathrm{~m}$ (Table 2). All the rice paddy fields were managed conventionally by local growers, and the rice variety "Hitomebore" in Maesawa and Otomo and "Sasa-nishiki" in Semine was grown from mid-May to midOctober. Insecticide input for all research fields was controlled, and an insecticide (dinotefuran) was sprayed once for pests attacking rice grains in early August in every research year by a radio-controlled helicopter. Another insecticide (chlorantraniliprole) was applied to all fields examined in mid-May, just before transplantation of rice seedlings by nurserybox application.

We checked the degree of hull-cracked rice grain occurrence (Online Resource Fig. S4) which influences pecky rice damage and depends on each rice variety. The level of pecky rice damage caused by S. rubrovittatus and the number of hullcracked rice grains were common among the rice varieties (Tabuchi and Sakurai 2019), and the degree of damage could be estimated by using the degree of hull-cracked rice grains regardless of the rice variety. However, the percentage of hullcracked rice grains among the current study regions did not exceed that of the original region of the model, thus we did not need to correct the damage level among regions.

We selected focal paddy fields in this study which contained no graminoid weeds, such as Echinochloa spp. (Poales: Poaceae), or Cyperaceae weeds. These plants are suitable host plants for $S$. rubrovittatus, and enhance pecky rice damage (Kashin et al., 2009).

To confirm whether $S$. rubrovittatus actually caused pecky rice damage, and to investigate the species composition of heteropteran pests causing pecky rice damage, we conducted sweeping net surveys at selected rice paddy fields (Online Resource Table S1). Among the heteropterans sampled that can cause pecky rice damage within study regions, $80.4 \%$ (range: $46.7 \%-98.0 \%$ ) of the individuals were S. rubrovittatus. 
The pecky rice damage was investigated by collecting plants from 20 rice hills containing 32,131 rice grains on an average (range: 18,498 - 46,049 grains) from each rice paddy in every year. After hulling, brown rice grains were sifted through a $1.9 \mathrm{~mm}$ mesh. We counted the number of intact and damaged grains and calculated the degree of rice damage.

\section{Data analyses and model evaluation}

All the analyses were conducted using R 4.0.0 (R Core Team 2020). The predictive model of pecky rice damage (Tabuchi et al. 2017) is shown as the following equation:

$y=-0.09+40.05 \star$ Source habitat $+52.7 \star$ Soybean $-1.12 *$ Paddy field + RI year

where $y$ is arcsine-transformed pecky rice damage at given points, -0.09 is a fixed intercept of the model. The areas of source habitat, soybean, and paddy field in Equation (1) were the data calculated within a 300-m radius of research points $\left(\mathrm{km}^{2}\right)$, and values to the left of asterisks are coefficients of the model. These are the fixed parts of the model. In Equation (1), RI year is the year-specific random intercept described by year-specific variance with a normal distribution, and is the random part of the model. The yearly random intercepts were larger in the order of 2011, 2012, and 2013.

Before constructing the adjusted predictive model, we examined the parallel slopes of the regression lines for the regions and years by One-Way Multivariate Analysis of Covariance to check whether we could combine data from four regions for the four research years of current study and three years of previous study (Tabuchi et al. 2017). The arcsine-transformed percentage of pecky rice was examined as a response variable, and the area of land uses (source habitat, soybean, and rice paddy, which were important factors in the original predictive model of rice damage (Tabuchi et al. 2017)), region, research year, and their two-way interactions were analyzed as fixed factors.

The percentage of pecky rice damage was analyzed using a general linear mixed model in the nlme package (Pinheiro et al. 2020). The percentage of pecky rice damage was arcsine transformed, and a Gaussian error distribution was applied. In the model, the area $\left(\mathrm{km}^{2}\right)$ of soybean fields and rice paddy fields, and source habitat of $S$. rubrovittatus, which included pastures and graminoid-dominated fallow fields, were set as fixed factors. To construct a single common predictive model applicable in different regions and years, regions and research years were treated as two levels of random factors in the model: intercepts were calculated for the three regions and each research year in each region, so that the model had three region-specific random intercepts and 8 year-specific random intercepts (three for Maesawa (2011-2013), three for Semine (2016-2018) and two for Otomo (2018 and 2020)).

As mentioned above, the predictive model of pecky rice damage (Tabuchi et al. 2017) is only composed of land use variables. We assigned values that were obtained from the current study to the original model and calculated the predicted value of pecky rice damage. In Tabuchi et al. (2017), the random intercept was assigned the highest value in 2011 to obtain a conservative output. After that, to adjust the coefficients of each fixed factor to the data of the current study regions, we prepared an adjusted predictive model. Using data from the current study and the original study (Tabuchi et al. 2017), we analyzed the pecky rice damage and prepared the model. The area of source habitat, soybean field, and rice paddy fields within $300 \mathrm{~m}$ of the sampled field were set as fixed factors, and research year and regions were set as random factors. We ranked the plausibility of the models using Akaike's Information Criterion adjusted for small sample sizes (AICc). If the difference in the $\triangle \mathrm{AICC}$ was less than 2, then that model was considered more relevant than the other models (Burnham and Anderson 2002). Multicollinearity of the model (i.e., whether the variance inflation factor was less than 10; Dormann et al. 2013) was also checked. When the adjusted model was statistically significant, we calculated the predicted value of pecky rice damage. 
To evaluate the suitability of the extrapolation of the original model and whether the predicted values from the adjusted model improved on the original model, post hoc comparisons of the observed and predicted values calculated by the models were performed by a general linear mixed model by using package nlme. We compared both the data of the current study only, and the current and the original data combined. Research year and region were added to the model as random factors. The $R^{2}$ values for the mixed models were calculated using the function r.squaredGLMM from the package MuMIn (Barton 2020). The predictive performance of the adjusted model for unknown data was evaluated by 3-fold cross validation.

The accuracies of the original and the adjusted models for predicting the amount of first grade brown rice which is the greatest importance to local farmers were measured and compared by the area under the receiver operating characteristic (AUC) curve (Akobeng 2007) using observed and predicted values in the R package ROCR (Sing et al. 2020). For the original and the adjusted models, positive and negative classification errors, and the proportion of correct predictions (sensitivity, specificity, and positive and negative predictive values), were calculated to determine the relevance of the model.

To demonstrate the sensitivity of the adjusted model that shows how the prediction values of the model behave, we calculated the model prediction values for the lowest and highest risk cases, which were determined from the lowest and highest random intercepts. The predicted values were fitted using minimum, average, and maximum of the area of source habitat and soybean fields in the data that were shown as significant factors in the original predictive model in Tabuchi et al. (2017). In this calculation, the average area of rice paddy was used in all cases.

\section{Priority area map construction}

On the basis of a predictive spatial model, we constructed a map showing the potential priority areas for pecky rice damage. Because we only investigated the surrounding land use of fields within $300 \mathrm{~m}$ radii of research points, for each region and surrounding wider area (Fig. 1) other than the research fields, we determined the land use of each field by visualization. Satellite and aerial imagery taken from DigitalGlobe, which was available as a base layer in ArcGIS 10.4 (ESRI 2016) in June 2012 for Maesawa region, and in August 2017 for Semine region was used as a reference. For Otomo, we used the satellite imagery from Google Earth taken in October 2017. The results of direct observations of land use types were used as a reference. In total, 18,319 agricultural fields and other land use areas were determined and mapped. To construct the priority area map, the focal agricultural area was divided into hexagons with each side being $300 \mathrm{~m}$, which is the maximum size fitting inside a circle with a 300-m radius. Only hexagons that included agricultural fields were selected. To rank the risk to rice paddy fields in each hexagon, the area of each land use type within each hexagon was calculated, and this data approximated a circle of diameter $600 \mathrm{~m}$. The area of land use in each hexagon was assigned to the model for extrapolation to the surrounding area. The predicted values of pecky rice damage were classified according to the four brown rice grades and then mapped using color-coordinated hexagons.

\section{Results}

When we checked the parallel slopes of regression lines to combine the data from two new regions with four years and one previous region with three research years, the model indicated that no significant regional difference was observed (LM: $F=$ $0.091, \mathrm{df}=1, p=0.789)$, and no significant difference observed for the two-way interactions relating each land use, and region (LM: $p>0.05$ ) (Online Resource Figs. S1 and S5, Online Resource Table S2) on the arcsine-transformed percent of pecky rice damage, supporting the existence of an inter-regional common pattern. On the other hand, only the two-way interaction of source habitat and region was significant (LM: $F=15.21, \mathrm{df}=5, p=0.047$ ) (Online Resource Table S2), indicating that the research year had a significant effect on the coefficient between the arcsine transformed pecky rice 
damage and the area of source habitat. For the combined data of the current study and that of Tabuchi et al. (2017) which contained 93 samples, the comparison of observed and predicted values for the pecky rice damage by the original predictive model was statistically significant (Fig. 2a), indicating that an inter-regionally common pattern was observed. However, when only the data of the two current study regions was assigned to the original predictive model of pecky rice damage, the relationship varied and was not statistically significant (Fig. $2 b$, LMM: $n=46, \chi^{2}=0.705, p=0.401$ ). The AUC value was 0.50 indicating the model demonstrated a chance result (Table 3 ).

For the 93 samples of the combined data of current study and Tabuchi et al. (2017), we created an adjusted predictive model of rice damage, for which the model equation is shown as below:

$y=-0.09+40.05 *$ Source habitat $+52.7 *$ Soybean $-1.12 *$ Paddy field + RI year

$y=0.03+32.07 \star$ Source habitat $+44.5 \star$ Soybean $+2.6 *$ Paddy field $+R I$ region \& year

$$
\mathrm{RI} \text { region \& year }=\mathrm{u}_{\text {region }}+\mathrm{w}_{\text {year in region }}
$$

where $y$ is the arcsine-transformed pecky rice damage at given points, 0.03 is the fixed intercept of the model, and the areas of source habitat, soybean, and paddy field were calculated within a 300-m radii of research points $\left(\mathrm{km}^{2}\right)$. These were the fixed part of the model. The RI region \& year was the random intercept (Equation 2.1), which consisted of regionspecific intercepts ( $\left.u_{\text {region }}\right)$ and year-specific random intercepts in each region ( $\left.w_{\text {year in region }}\right)$. All parameters of the original model were selected in the AIC-based best model (Table 4), indicating that there was an inter-regional common relationship between landscape factors and rice damage. In the adjusted model, the coefficients of source habitat and soybean slightly decreased by 7.98 point and 8.2 point, respectively. The second-best model consisted of the area of source habitat and soybean field (Table 4).

By comparing the relationship between the observed and predicted value of the pecky rice damage, the $R^{2}$ value of the adjusted model improved by $14 \%$ (Figs. 2a and 2c) over the $R^{2}$ value of the original model (Tabuchi et al. 2017). The AUC value improved from 0.73 for the original model to 0.79 for the adjusted model, indicating that both models had moderate accuracy (Table 3). When comparing the sensitivity, specificity, and positive and negative predictive values of the original model to the combined data, the specificity and positive predictive values were improved by the adjusted model.

The relationship between the observed and predicted value of the pecky rice damage from current study data was statistically significant in the adjusted model (Fig. 2d, LMM: $n=46, \chi^{2}=17.30, p<0.001$ ). The AUC value of the adjusted model for only the data of current study was improved to 0.74 (Table 3 ). In the adjusted model, the specificity and positive predictive values were improved, indicating that the adjusted model was more accurate for specificity and predicted true positives (Table 3). From the three-fold cross validation, the R-squared value between observed and predicted the pecky rice damage was $0.50 \pm 0.09$ (mean $\pm S D$ ), and the mean AUC value $\pm S D$ was $0.73 \pm 0.13$, indicating model accuracy was moderate for unknown data.

The predicted values of pecky rice damage in the adjusted model became higher with an increase in the area of source habitat and soybean fields (Fig. 3). Regardless of the lowest (Semine region in 2018) and the highest (Maesawa region in 2011) risk cases, the rice grade fell into second grade or below in the case of the maximum area of source habitat, indicating that the risk of possible price decline is high under this situation.

The potential priority areas were mapped using the model (Fig. 4). The 95 priority areas were selected from among 380 hexagons. Thus, the priority areas for pest management were successfully visualized. The model prediction varied 
between the highest- and the lowest-risk cases, and 167 and 49 priority areas were selected, respectively (Online Resources Fig. S6).

\section{Discussion}

Our study supported the hypothesis that an inter-regional common relationship was observed between landscape factors and crop damage by a pest across agricultural landscapes. The original predictive model was applicable to all regions within the current study and the original region (Fig. 2a, Table 4), suggesting that the original model is able to predict rice damage with moderate accuracy. However, direct extrapolation of the original damage prediction model to only the extrapolated regions of the current study was not straightforward (Fig. 2b, Table 4), resulting in lower accuracy than in the original region of the model. Data from the current study did not include a degree of damage higher than four in the arcsine-transformed pecky rice damage, thus, model accuracy may vary in the region or year of higher risk of pecky rice damage. Previous studies dealing with both empirical and theoretical argument suggest that effective spatial scale and associated biological responses against landscape factors would differ between regions even with the same species (reviewed in Miguet et al. 2016) and, thus, extrapolation would not be easy. The current study examined identical species using the same spatial scale in several research regions. We empirically demonstrated that the effective spatial scale of the pest was inter-regionally applicable in relation to landscape factors and crop damage by $S$. rubrovittatus, although other spatial scales were not examined.

Our results showed that adjustment of the parameter coefficients of the predictive model by adding additional regional data can improve predictions when we use models developed over a wider area. The relationships between landscape factors and responses of different arthropod pests are highly dependent on the pest taxa and the nature of their trophic interactions (e.g. Tscharntke et al. 2016). The trophic interaction of our study between S. rubrovittatus and its natural enemies is relatively simple compared with previous studies. Irrigated rice fields are the most biologically diverse agroecosystems, and regional and local conditions affect rice arthropod communities (Dominik et al. 2017, 2018). However, insecticides also reduce species diversity and abundance in rice-agroecosystems (Yushima et al 1973; Goka and Hayasaka 2013; Sattler et al. 2020). Top-down regulation of $S$. rubrovittatus is not strongly expected in this study, because the population of such natural enemies is suppressed by conventional management such as spraying insecticides (Pimentel et al. 1992; Heong and Schoenly 1998; Schoenly et al. 2010) and the species has almost no specific natural enemies other than spiders (Takada et al. 2012). Stenotus rubrovittatus seldom reproduces in rice paddy fields (Tabuchi et al. 2015), so the number of individuals invading rice paddy fields is mostly determined by the source habitat of the surrounding landscape. Therefore, our study may not be directly applicable to other pests, crops, and agricultural landscapes. However, our result suggests that inter-regional commonality of biological responses to landscape factors may exist at some scales in the population dynamics of pests and organisms that have similar ecological characteristics with S. rubrovittatus.

In this study, there were several common landscape factors. For example, we carefully selected regions with rice-dominated landscapes and similar major crop composition, rice growing season, and management intensity for insect pests (i. e. the number of pesticide applications). In addition, the local environment and management intensity of pests and weeds in each field were very similar, and the major insect pest species composition was similar. In contrast, several factors such as the research year and associated climate condition, and the quality of source habitat of the pest (i.e., species composition of graminoid weeds) differed between the regions examined. Furthermore, the percentage of $S$. rubrovittatus among major grain attacking pest species in the regions varied. These factors might change the accuracy of the original predictive model of crop damage. However, the adjusted predictive model here could be assigned within $50 \mathrm{~km}^{2}$ in this study: similar biological responses of planthopper pests were shown at an equivalent spatial scale in the extra fine-grained Asian rice landscapes in China (Zou et al. 2019). Moreover, it was possible to extrapolate the predictive model over wider areas that had similar environmental conditions. For example, similar results on the relationships between $S$. rubrovittatus abundance 
and landscape factors at similar spatial scales were reported in two independent regions, which were $300 \mathrm{~km}$ apart (Yasuda et al. 2011; Takada et al. 2012). Over large areas of hundreds of kilometers, previous studies have shown common patterns in the response of landscape factors and biological responses of arthropods (Gardiner et al. 2009; Lacasella et al. 2017; Zhang et al. 2018), although there was no attempt to extrapolate using empirical validation like the current study. Therefore, the adjusted predictive model may be able to extrapolate even further from the area of current study if the environmental and biological context is similar.

Further improvement of the accuracy and sensitivity of the predictive model should however be considered. The adjusted model prediction varied among the lowest and highest risk cases (Fig. 3, Online Resources Fig. S6), indicating regional and other related factors, which were not dealt with in this study, affecting the model fitting. The prediction accuracy of our adjusted predictive model was demonstrated to be moderate, and the accuracy of the model might be improved by incorporating such factors. Our predictive model only included land use; therefore, incorporating values relating to management practices or pre-cropping climate conditions and other unknown factors may improve the model's accuracy in the future. A combination of land use, climate condition, and pest management practices affects population dynamics in cotton pests (Zhang et al. 2018) and soybean aphids (Lacasella et al. 2017), which is reasonable to explain the population dynamics of poikilothermic organisms. Previous studies of rice-attacking pentatomids in Japan suggested that temperature of rice heading season and grain growing season have a positive effect on the total pecky rice damage of several pentatomid species, including S. rubrovittatus in southwestern Japan (Sugiura et al. 2002) and the abundance of another mirid species T. caelestialium in northern Japan (Kawasaki et al. 2007). On the other hand, elevation and temperatures were not statistically significant beyond regions, indicating these factors did not affect the predicting model in this study. Our study had only three regions, and research fields were clustered in each region, which may have resulted in less variability in climatic conditions. Therefore, the effect of temperature might not be detected in the current data set, and adding more regions, temperature, and other climatic conditions might be able to improve the predictive model as one of the factors explaining the pecky rice damage.

Our spatially explicit predictive model of crop damage only included land use data without data on pest abundance, which allowed us to identify potential priority areas after the spatial arrangement of arable fields in a certain year has been determined. The predicted value for pecky rice damage was not sensitive enough for a quantitative prediction (Fig. 2); however, the model worked accurately enough to predict whether the brown rice would be first grade, which is the most important concern for local farmers. Thus, our results will be applicable for local farmers and others in determining appropriate pest management policies, to support decision-making in several regions. This model and the priority area map will help to determine the areas that should receive insecticide applications and the number of applications that an area may require. Farmers usually need to optimize the allocation of resources necessary to mitigate crop damage by spraying insecticides at the most effective period because of limited time and labor. By using the current predictive model, they will be able to focus their labor in high priority areas and might be able to omit spraying insecticides for low priority areas, which may lead to savings in costs and labor.

In summary, a common single predictive model for predicting crop damage using land use data within an empirically determined spatial scale can be applied in independent regions in the agricultural landscapes. Agricultural landscapes are anthropogenically managed, especially in regions that grow grain intensively. Under such relatively well-managed environments, it is valuable to know how to extrapolate spatially explicit predictive models after empirically examining the environmental conditions among regions. To achieve regional pest management efficiently, we will need to incorporate the ecological understanding of this study to model pest systems. Here, crop damage is usually related to pest abundance, so it was examined as an extended biological response of pests to landscape factors. Biological responses include a wide variety of factors such as species occurrence, abundance, and breeding (Miguet et al. 2016), and cover several ecosystem services such as pest suppression and pollination. Little is known about the inter-regional common relationships of such responses and few studies have looked at the challenges of extrapolation, so further work is needed in this area. From the point of view of application, several environmental hazards such as plant pathogens (Krupinsky et al. 2002; Kondoh et al.

Page $10 / 20$ 
2015), wildlife (Saito et al. 2012), vector-borne diseases (Eisen and Eisen 2011), and alien invasive species (Giovanelli et al. 2008, Lacasella et al. 2017) have been dealt with previous studies, and it might be possible to develop early-warning or preventative guidelines by offering region-wide management options. Such trials will be done in the near future and the application of the model will be validated in further studies.

\section{Declarations}

\section{Funding}

Part of this work was funded from Ministry of Agriculture, Forestry and Fisheries (Grant Number: JPJ000418), and by KAKENHI grant from the Japan Society for the Promotion of Science, Japan (no. 16H05061).

\section{Conflicts of interest/Competing interests}

The authors state they have no conflicts of interest.

\section{Ethics approval}

Not applicable.

\section{Consent to participate}

Not applicable.

\section{Consent for publication}

Not applicable.

\section{Availability of data and material}

Data available via the GitHub Repository https://github.com/KTab6464/DamagePrediction_data_2021

\section{Code Availability}

Not applicable.

\section{Author contributions}

KT conceived the idea and designed the experiments. All authors collected the data; KT analyzed the data and led the writing of the manuscript. All authors contributed critically to the drafts and gave final approval for publication. 


\section{References}

Akobeng AK (2007) Understanding diagnostic tests 3: receiver operating characteristic curves. Acta Pædiatrica 96(5):644647

Barton K (2020) MuMIn: Multi-Model Inference. R package version 1.43.17. Available from https://CRAN.Rproject.org/package=MuMIn accessed 16 Sep 2020)

Brownstein J, Skelly D, Holford T, Fish D (2005) Forest fragmentation predicts local scale heterogeneity of Lyme disease risk. Oecologia 146(3):469-475

Burnham KP, Anderson DR (2002) Model Selection and Multimodel Inference. A Practical Information-Theoretic Approach. Springer-Verlag, New York

Dominik C, Seppelt R, Horgan FG, Marquez L, Settele J, Václavík T (2017) Regional-scale effects override the influence of fine-scale landscape heterogeneity on rice arthropod communities. Agric., Ecosyst. Environ. 246 (Supplement C) :269-278

Dominik C, Seppelt R, Horgan FG, Settele J, Václavík T, Corley J (2018) Landscape composition, configuration, and trophic interactions shape arthropod communities in rice agroecosystems. Journal of Applied Ecology 55(5):2461-2472

Dormann CF, Elith J, Bacher S et al (2013) Collinearity: a review of methods to deal with it and a simulation study evaluating their performance. Ecography 36(1):027-046

Eisen L, Eisen RJ (2011) Using geographic information systems and decision support systems for the prediction, prevention, and control of vector-borne diseases. Annu. Rev. Entomol. 56(1):41-61

ESRI (2016) ArcGIS desktop: release 10.4. Environmental Systems Research Institute, Redlands, CA, USA

FAO (2019) World Food and Agriculture - Statistical pocketbook

Fisheries MoAFa (2001) Regulations for the Agricultural Product Standards (Notification No. 244 of the Ministry of Agriculture, Forestry and Fisheries of Japan). Available from http://www.maff.go.jp/j/kokuji_tuti/kokuji/k0001439.html accessed 16 Sep 2020)

Gardiner MM, Landis DA, Gratton C et al (2009) Landscape diversity enhances biological control of an introduced crop pest in the north-central USA. Ecological Applications 19(1):143-154

Giovanelli JGR, Haddad CFB, Alexandrino J (2008) Predicting the potential distribution of the alien invasive American bullfrog (Lithobates catesbeianus) in Brazil. Biological Invasions 10(5):585-590

Goka K, Hayasaka D (2013) Can the ecological risk assessment of pesticide conserve biodiversity?: perspective through the mesocosm test as a high tier risk assessment. JpnJ Environ Toxicol 16(2):21-28

Hayashi H, Nakazawa K (1988) Studies on the bionomics and control of the sorghum plant bug, Stenotus rubrovittatus Matsumura (Hemiptera: Miridae) 1. Habitat and seasonal prevalence in Hiroshima Prefecture. Bull Hiroshima Prefect Agric Exp Stn 51:45-53

Heong KL, Schoenly KG (1998) Impact of insecticides on herbivore-natural enemy communities in tropical rice ecosystems. In: Haskell PT and McEwen P (eds) Ecotoxicology: pesticides and beneficial organisms. Kluwer, Dordrecht, Netherlands, pp 381-403 
Hori M, Namatame M (2013) Host plant volatiles responsible for the invasion of Stenotus rubrovittatus (Heteroptera: Miridae) into paddy fields. Journal of Applied Entomology 137(5):340-346

Kashin J, Hatanaka N, Ono T, Oyama J, Kidokoro T (2009) Effect of Scirpus juncoides Roxb. var. ohwianus on occurrence of sorghum plant bug, Stenotus rubrovittatus (Matsumura) (Hemiptera: Miridae) and pecky rice. Jpn. J. Appl. Entomol. Zool. 53(1):7-12

Kawasaki T, Watanabe K, Domon K, Ogata E, Yoshimura T (2007) Relationship between occurrence of rice leaf bug, Trigonotylus caelestialium (Heteroptera: Miridae) and meteorogical conditions. Annual Report of Plant Protection of North Japan 2007(58):84-87

Kondoh H, Yamanaka T, Saito S, Shoda-Kagaya E, Makino Si (2015) Development of a hazard map for oak wilt disease in Japan. Agric. For. Entomol. 17(2):205-213

Krupinsky JM, Bailey KL, McMullen MP, Gossen BD, Turkington TK (2002) Managing plant disease risk in diversified cropping systems. Agronomy Journal 94(2):198-209

Lacasella F, Marta S, Singh A et al (2017) From pest data to abundance-based risk maps combining eco-physiological knowledge, weather, and habitat variability. Ecological Applications 27(2):575-588

Lee JG, Hong SS, Kim JY, Park KY, Lim JW, Lee JH (2009) Occurrence of stink bugs and pecky rice damage by stink bugs in paddy fields in Gyeonggi-do, Korea. Korean J. Appl. Entomol. 48(1):37-44

Meentemeyer R, Rizzo D, Mark W, Lotz E (2004) Mapping the risk of establishment and spread of sudden oak death in California. Forest Ecology and Management 200(1-3):195-214

Miguet P, Jackson HB, Jackson ND, Martin AE, Fahrig L (2016) What determines the spatial extent of landscape effects on species? Landscape Ecology 31(6):1177-1194

Miller JR, Turner MG, Smithwick EAH, Dent CL, Stanley EH (2004) Spatial Extrapolation: The Science of Predicting Ecological Patterns and Processes. Bioscience 54(4):310-320

Moraga AD, Martin AE, Fahrig L (2019) The scale of effect of landscape context varies with the species' response variable measured. Landscape Ecology 34(4):703-715

Murray JV, Low Choy S, McAlpine CA, Possingham HP, Goldizen AW (2011) Evaluating model transferability for a threatened species to adjacent areas: Implications for rock-wallaby conservation. Austral Ecol., 1. pp. 76-89

Nagasawa A, Higuchi H (2012) Suitability of poaceous plants for nymphal growth of the pecky rice bugs Trigonotylus caelestialium and Stenotus rubrovittatus (Hemiptera: Miridae) in Niigata, Japan. Appl. Entomol. Zool. 47(4):421-427

Paik CH, Choi MY, H. Y. Seo, Lee GH, Kim JD (2007) Stink bug species and host plants occurred in fallow lands for rice product regulation. Korean J. Appl. Entomol. 46(2):221-227

Pimentel D, Stachow U, Takacs DA et al (1992) Conserving biological diversity in agricultural/forestry systems. Bioscience 42(5):354-362

Pinheiro J, Bates D, DebRoy S, Sarkar D, Team RC (2020) nlme: Linear and nonlinear mixed effects models. R package version 3.1-148. Available from https://CRAN.R-project.org/package=nlme accessed 16 Sep 2020)

Rusch A, Valantin-Morison M, Sarthou JP, Roger-Estrade J (2013) Effect of crop management and landscape context on insect pest populations and crop damage. Agric., Ecosyst. Environ. 166(0):118-125

Page $13 / 20$ 
Saito M, Momose H, Mihira T (2011) Both environmental factors and countermeasures affect wild boar damage to rice paddies in Boso Peninsula, Japan. Crop Protection 30(8):1048-1054

Saito M, Momose H, Mihira T, Uematsu S (2012) Predicting the risk of wild boar damage to rice paddies using presenceonly data in Chiba Prefecture, Japan. Int. J. Pest Manage. 58(1):65-71

Sattler C, Gianuca AT, Schweiger O, Franzén M, Settele J (2020) Pesticides and land cover heterogeneity affect functional group and taxonomic diversity of arthropods in rice agroecosystems. Agric., Ecosyst. Environ. 297

Schellhorn NA, Parry HR, Macfadyen S, Wang Y, Zalucki MP (2015) Connecting scales: Achieving in-field pest control from areawide and landscape ecology studies. Insect Science 22(1):35-51

Schoenly KG, Cohen JE, Heong KL, Litsinger JA, Barrion AT, Arida GS (2010) Fallowing did not disrupt invertebrate fauna in Philippine low-pesticide irrigated rice fields. Journal of Applied Ecology 47(3):593-602

Sing T, Sander O, Beerenwinkel N, Lengauer T (2020) ROCR: visualizing classifier performance in R. Bioinformatics 21(20):7881

Sugiura N, Koga S, Suzuki Y (2002) Relationship between occurrence of pecky rice caused by rice bugs and meteorological conditions in Kumamoto Prefecture. Kyushu PI. Prot. Res. 48:54-59

Tabuchi K, Ichita T, Ohtomo R et al (2015) Rice bugs in the Tohoku region: the occurrence and their damage from 2003 to 2013. Bulletin of Tohoku Agricultural Research Center 117:63-115 (in Japanese with English summary)

Tabuchi K, Murakami T, Okudera S et al (2017) Predicting potential rice damage by insect pests using land use data: A 3year study for area-wide pest management. Agric., Ecosyst. Environ. 249:4-11

Tabuchi K, Sakurai T (2019) Relationship between the occurrence of split-hull paddies and incidence of pecky rice damage caused by adults of two mirid pests, Stenotus rubrovittatus and Trigonotylus caelestialium (Hemiptera: Miridae): a comparison of eight rice varieties. Appl. Entomol. Zool. 63(4):181-188

Takada MB, Yoshioka A, Takagi S, Iwabuchi S, Washitani I (2012) Multiple spatial scale factors affecting mirid bug abundance and damage level in organic rice paddies. Biological Control 60(1):169-174

Takahashi Y, Kikuchi H (2013) Effect of Echinochloa spp. heading after August in paddy field on occurrence of pecky rice caused by Stenotus rubrovittatus. Annual Report of Plant Protection of North Japan 64:126-129

Takeda A, Oku K, Sugeno W, Yasuda T, Watanabe T (2012) Monitoring sorghum plant bug, Stenotus rubrovittatus (Matsumura) (Hemiptera: Miridae), with a synthetic sex pheromone trap in paddy fields. Jpn. J. Appl. Entomol. Zool. 56(1):26-29

Tscharntke T, Karp DS, Chaplin-Kramer R et al (2016) When natural habitat fails to enhance biological pest control - Five hypotheses. Biological Conservation 204:449-458

Vanreusel W, Maes D, Van Dyck H (2007) Transferability of species distribution models: a functional habitat approach for two regionally threatened butterflies. Conservation Biology 21(1):201-212

Winqvist C, Bengtsson J, Aavik T et al (2011) Mixed effects of organic farming and landscape complexity on farmland biodiversity and biological control potential across Europe. Journal of Applied Ecology 48(3):570-579

Yasuda M, Mitsunaga T, Takeda A et al (2011) Comparison of the effects of landscape composition on two mirid species in Japanese rice paddies. Appl. Entomol. Zool. 46(4):519-525

Page $14 / 20$ 
Yushima K, Kiritani K, Kanazawa J (1973) Ecosystems and Agrochemicals. Iwanami Shoten, Publishers, Tokyo

Zhang W, Lu Y, van der Werf W et al (2018) Multidecadal, county-level analysis of the effects of land use, Bt cotton, and weather on cotton pests in China. P. Natl. Acad. Sci. USA 115(33):E7700-E7709

Zharikov Y, Lank DB, Cooke F (2007) Influence of landscape pattern on breeding distribution and success in a threatened Alcid, the marbled murrelet: model transferability and management implications. Journal of Applied Ecology 44(4):748-759

Zou Y, Kraker J, Bianchi FJJA et al (2019) Do diverse landscapes provide for effective natural pest control in subtropical rice? Journal of Applied Ecology 57(1):170-180

\section{Tables}

Table 1 Summary of research locations.

\begin{tabular}{|c|c|c|c|c|c|c|c|}
\hline $\begin{array}{l}\text { Location } \\
\text { (Region, City, } \\
\text { Prefecture) }\end{array}$ & Latitude & Longitude & Year & $\begin{array}{l}\text { Total no. } \\
\text { of rice } \\
\text { fields } \\
\text { examined } \\
\end{array}$ & $\begin{array}{c}\text { Mean } \\
\text { temperature } \\
\left(\mathrm{C}^{\circ}\right)\end{array}$ & $\begin{array}{c}\text { Mean } \\
\text { precipitation } \\
\text { (mm/month) }\end{array}$ & $\begin{array}{l}\text { Elevation } \\
(\mathrm{m})\end{array}$ \\
\hline $\begin{array}{l}\text { Maesawa, } \\
\text { Oshu, Iwate 1) }\end{array}$ & 39.07267 & 141.10849 & 2011-2013 & 47 & 20.3 & 145.1 & 87.9 \\
\hline $\begin{array}{l}\text { Otomo, } \\
\text { Rikuzentakata, } \\
\text { Iwate }\end{array}$ & 38.99107 & 141.69709 & $2018 \& 2020$ & 18 & 20.1 & 142.6 & 10.8 \\
\hline $\begin{array}{l}\text { Semine, } \\
\text { Kurihara, } \\
\text { Miyagi }\end{array}$ & 38.65049 & 141.05932 & $2016-2018$ & 28 & 20.3 & 157.3 & 9.0 \\
\hline
\end{tabular}

1) Data from Tabuchi et al (2017)

2) Data of current study

Latitude and longitude are centroids of research fields in each location (datum: WGS84)

Mean temperature and precipitation averaged throughout the rice-growing season from May to September across all research years of each region

Meteorological data were obtained from Japan Meteorological Agency

(https://www.data.jma.go.jp/obd/stats/etrn/index.php)

Elevation is based on the digital elevation model of the $5 \mathrm{~m}$ mesh (DEM5a) data provided by Geospatial Information Authority of Japan (https://maps.gsi.go.jp/)

Table 2 Summary of fields examined in different regions

\begin{tabular}{|c|c|c|c|c|}
\hline $\begin{array}{l}\text { Location } \\
\text { (Region, City, } \\
\text { Prefecture) }\end{array}$ & $\begin{array}{c}\text { Average area of rice } \\
\text { paddy field examined } \pm \\
\text { SE (ha) } \\
\text { (n) }\end{array}$ & $\begin{array}{c}\text { Average area of fields } \\
\text { investigated land use in each } \\
\text { year } \pm \text { SE (ha) } \\
(\mathrm{n})\end{array}$ & $\begin{array}{c}\text { Average } \\
\text { distance } \\
\text { between fields } \\
\pm \mathrm{SE}(\mathrm{m})\end{array}$ & $\begin{array}{l}\text { Mean } \\
\text { source } \\
\text { habitat } \\
(\%) \\
\text { (range) }\end{array}$ \\
\hline $\begin{array}{l}\text { Maesawa, } \\
\text { Oshu, } \\
\text { Iwate }\end{array}$ & $0.22 \pm 0.02 \mathrm{a}$ & $0.15 \underset{(3508)}{ \pm 0.002 \mathrm{~b}}$ & $810.6 \pm 27.4$ & $\begin{array}{l}14.65 \\
(3.55- \\
28.68)\end{array}$ \\
\hline $\begin{array}{l}\text { Otomo, } \\
\text { Rikuzentakata, } \\
\text { Iwate }\end{array}$ & $0.23 \pm 0.02 \mathrm{a}$ & $\begin{array}{c}0.11 \pm 0.003 \mathrm{c} \\
(1223)\end{array}$ & $559.6 \pm 16.1$ & $\begin{array}{c}0.32 \\
(0.13-0.53)\end{array}$ \\
\hline $\begin{array}{l}\text { Semine, } \\
\text { Kurihara, } \\
\text { Miyagi }\end{array}$ & $0.28 \pm 0.04 \mathrm{a}$ & $\begin{array}{c}0.16 \pm 0.005 \mathrm{a} \\
(1911)\end{array}$ & $596.1 \pm 89.8$ & $\begin{array}{l}9.34 \\
(0.84- \\
29.09) \\
\end{array}$ \\
\hline
\end{tabular}

Different letters in each column indicate significant differences $(p<0.001$ ) by one-way ANOVA with Tukey-Kramer HSD test. 
Table 3 Comparison of the model performance between the original and adjusted predictive models for the combined data and current study data

\begin{tabular}{llcccccccc}
\hline Data & Model & $R^{2}$ & RMSE & $\begin{array}{c}\text { Accuracy } \\
(\%)\end{array}$ & AUC & Sensitivity & Specificity & $\begin{array}{c}\text { Positive } \\
\text { predictive } \\
\text { value }\end{array}$ & $\begin{array}{c}\text { Negative } \\
\text { predictive } \\
\text { value }\end{array}$ \\
\hline $\begin{array}{l}\text { Combined } \\
(\mathrm{n}=93)\end{array}$ & Original & 0.323 & 0.157 & 72.0 & 0.73 & 61 & 75 & 37 & 89 \\
$\begin{array}{l}\text { Current } \\
\text { study }\end{array}$ & Odjusted & 0.466 & 0.118 & 77.4 & 0.79 & 67 & 80 & 44 & 91 \\
$\begin{array}{l}\text { (n= 46) } \\
\text { Odjinal }\end{array}$ & Adjusted & 0.285 & $-1)$ & 67.4 & 0.50 & 33 & 73 & 15 & 88 \\
\hline
\end{tabular}

1): the model was not significant (LMM, $t=0.839, p>0.05)$

Table 4 Summary of the top five linear mixed models describing the variation in the level of pecky rice with land use within a 300-m radius from each research point. The values of land use indicate model coefficients

\begin{tabular}{|c|c|c|c|c|c|c|c|c|c|c|c|}
\hline \multirow{2}{*}{$\Delta \mathrm{AICc}$} & \multirow{2}{*}{ Weight } & \multirow{2}{*}{$\mathrm{df}$} & \multirow{2}{*}{$\begin{array}{l}\text { Source } \\
\text { habitat }\end{array}$} & \multirow{2}{*}{ Soybean } & \multirow{2}{*}{$\begin{array}{l}\text { Paddy } \\
\text { field }\end{array}$} & \multirow{2}{*}{ Elevation } & \multicolumn{4}{|c|}{ Temperature } & \multirow{2}{*}{ Intercept } \\
\hline & & & & & & & May & June & July & August & \\
\hline - & 0.306 & 7 & $32.07^{* * *}$ & $44.52^{*}$ & 2.61 & - & - & - & - & - & 0.03 \\
\hline 1.63 & 0.135 & 6 & $32.20^{* * *}$ & $44.26^{*}$ & - & - & - & - & - & - & 0.28 \\
\hline 2.52 & 0.087 & 8 & $33.04^{* * *}$ & $45.70^{*}$ & 2.49 & - & 0.17 & - & - & - & -2.52 \\
\hline 2.72 & 0.078 & 8 & $32.40^{* * *}$ & $44.65^{*}$ & 2.74 & - & - & - & -0.04 & - & 0.73 \\
\hline 3.27 & 0.059 & 8 & $32.48^{* * *}$ & $44.78^{*}$ & 2.68 & - & - & - & - & -0.07 & 1.64 \\
\hline
\end{tabular}

$\dagger:<0.10, *:<0.05, * *:<0.01, * * *:<0.001$. Values without * or $\dagger$ are not significant Each value of the model was calculated by function "lme ()" of nlme package in $\mathrm{R}$ Bold characters indicate significant variables Temperature of September did not include due to high multicollinearity with that of August The variation inflation factors for all models showed no multicollinearity

\section{Figures}



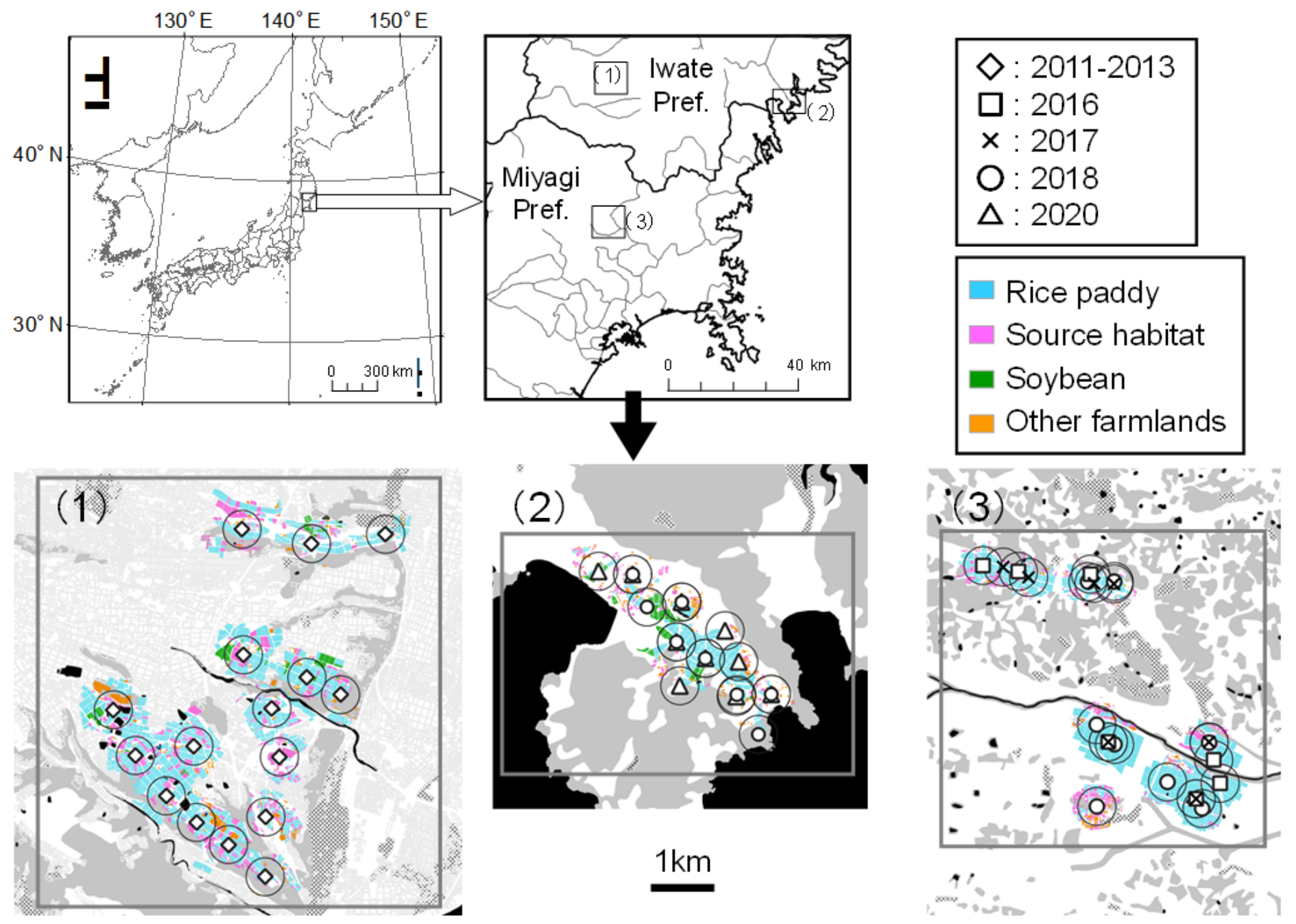

$1 \mathrm{~km}$

\section{Figure 1}

Map of the study area showing the positions of the rice paddy fields (white diamonds: previous study (Tabuchi et al. 2017), white squares, cross marks, circles and triangles: current study). Each circle centered on a point indicates a radius of 300 meters. (1) Maesawa region, Oshu city, (2) Otomo region, Rikuzen-takata city, and (3) Semine region, Kurihara city. Gray, black, and dotted areas represent forest, open water, and other land uses, respectively. Agricultural land uses were shown in colors. Squares indicate regions examined. 
(a)

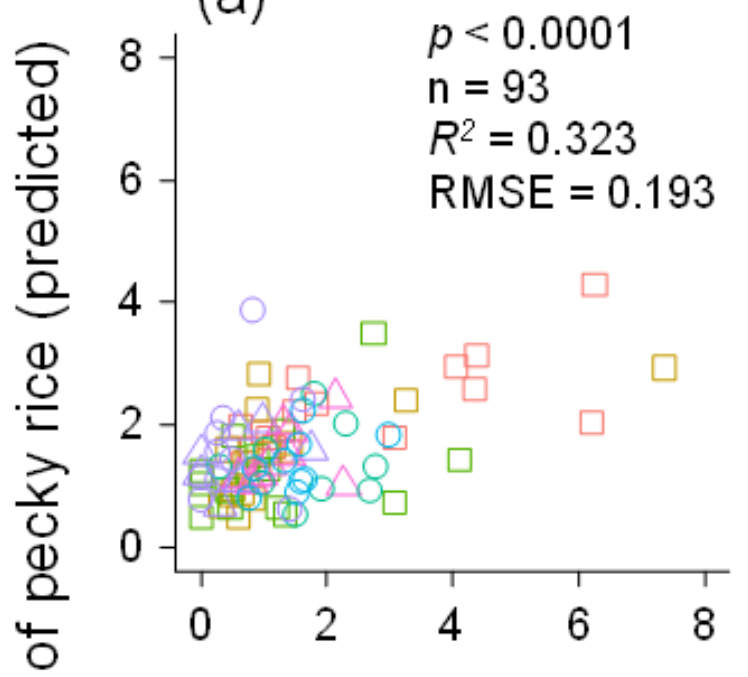

。 (c)

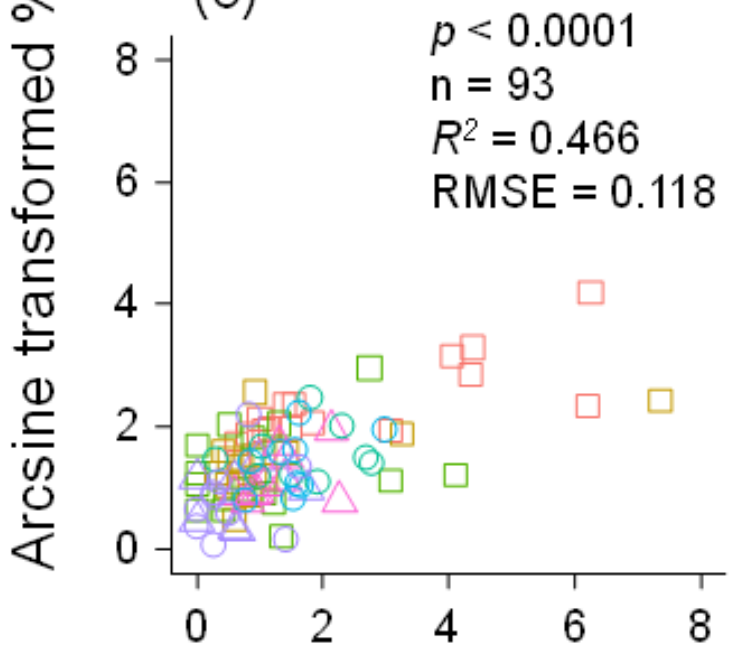

(b)

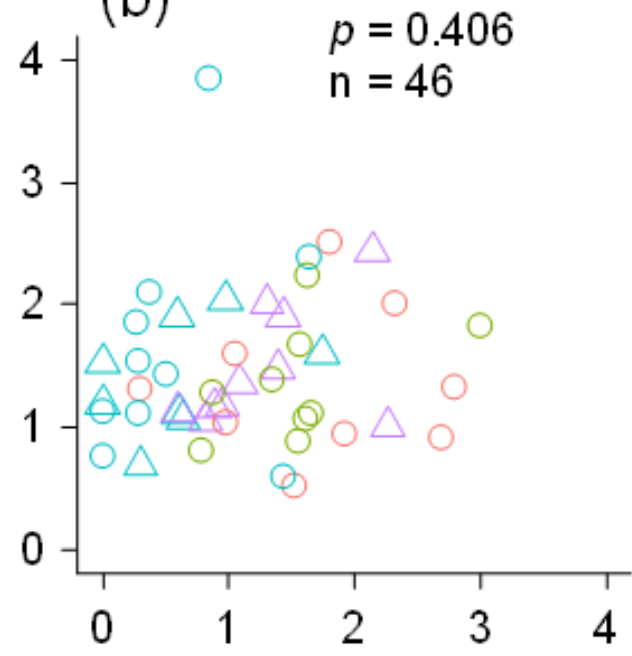

(d)

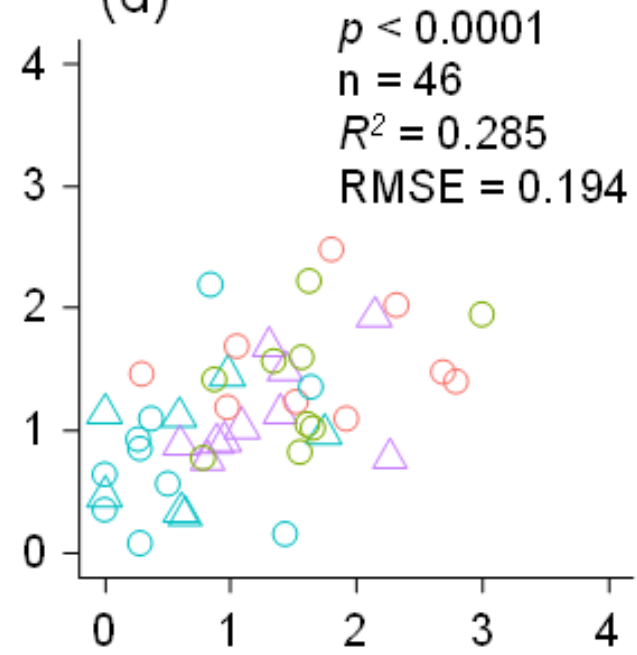

Region

o Semine

$\triangle$ Otomo

Maesawa

Year
2011
2012
2013
2016

- 2017

- 2018

- 2020 Arcsine transformed $\%$ of pecky rice (observed)

Figure 2

Post hoc comparison of the relationship between the observed and predicted values (\%) for pecky rice: the original model (a) for the combined data; and (b) the data of the current study; and the adjusted model (c) for the combined data; and (d) the data of current study. All the data were calculated after arcsine transformation. Reported R2 values are the conditional R2, which were estimated for the mixed models including the random effects 


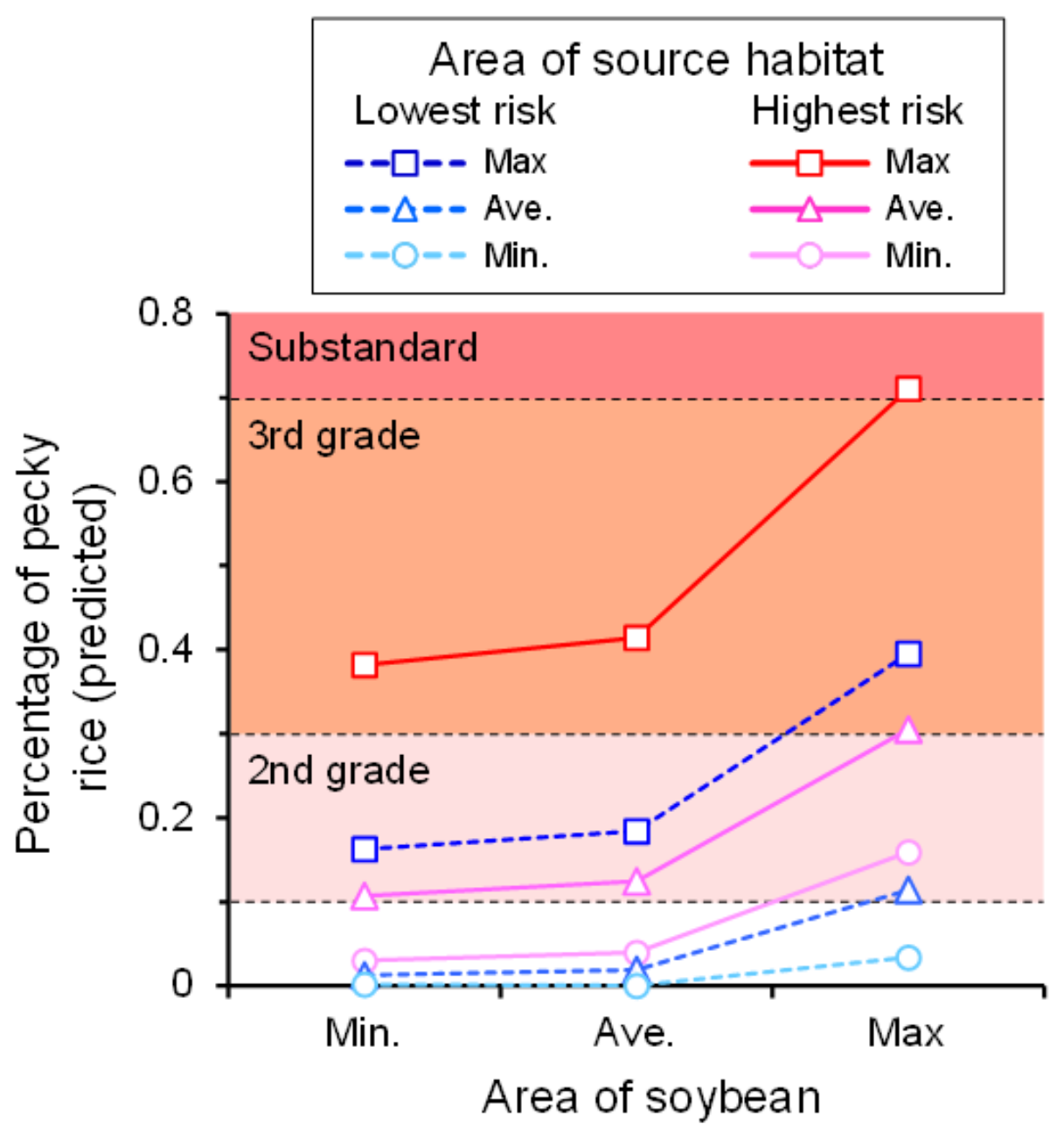

\section{Figure 3}

Percent of predicted pecky rice damage fitted by the adjusted model that represents the sensitivity of the model prediction. The lowest (Semine region in 2018, blue dot lines) and highest (Maesawa region in 2011, red and pink solid lines) risk cases are demonstrated. The fitted values were calculated using minimum, average, and maximum of the area of source habitat $(0.37,3.12$, and $8.32 \mathrm{ha})$ and soybean fields $(0,0.33,2.90 \mathrm{ha})$ with the average area of rice paddies ( $9.42 \mathrm{ha})$. Circles, triangles, and squares indicate the area of source habitat of minimum, average, and maximum data. The background color of the graph indicates the grades of the pecky rice damage 


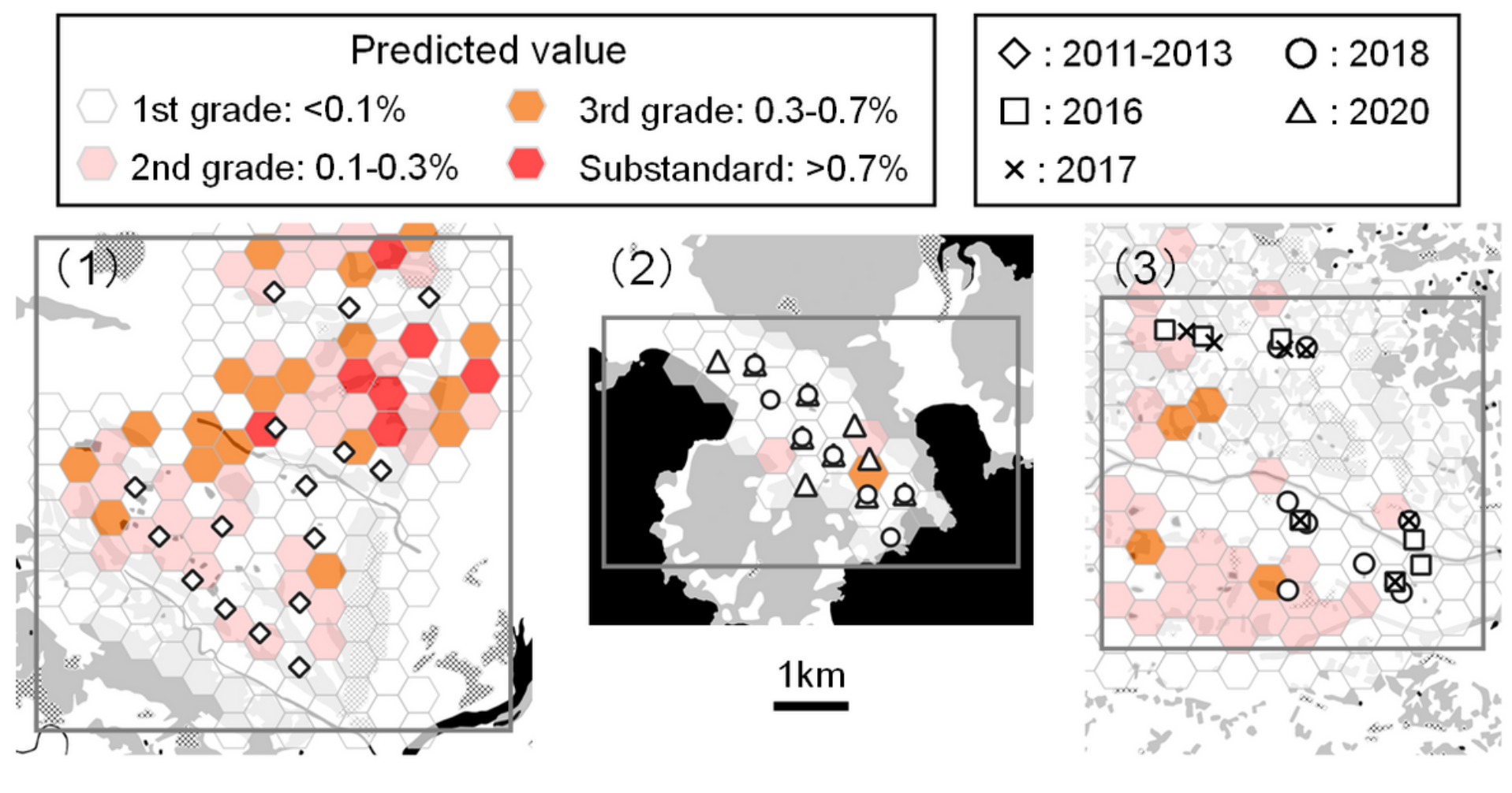

Figure 4

The priority area map of potential pecky rice damage in agricultural fields with grid layer of 300-m hexagons. Predicted values in hexagons were calculated by using the land use data in 2013 of Maesawa, 2018 of Otomo, and 2016 of Semine region, respectively. Shapes in the figure indicate the studied rice paddy fields in each research year. The model prediction of the map does not contain any region- and year-specific effects.

\section{Supplementary Files}

This is a list of supplementary files associated with this preprint. Click to download.

- SupplementaryTablesandFigures.docx 